\title{
Consequences of the BC Energy Step Code on Offsite Construction
}

\author{
Guido Wimmers ${ }^{1}$ and Alison Conroy ${ }^{2 *}$ \\ ${ }^{1}$ Associate Professor, Master of Engineering in Integrated Wood Design, University of Northern \\ British Columbia \\ ${ }^{2}$ PhD candidate, Department of Natural Resources and Environmental Studies, University of \\ Northern British Columbia \\ *Corresponding author's e-mail: guido.wimmers@unbc.ca
}

\begin{abstract}
In Canada, off-site construction is still the exception rather than the norm when it comes to wood construction. In Europe's Alpine Region or Scandinavian countries, off-site construction is standard when it comes to wood construction. This paper will focus on the reasons why Canada's wood construction industry will shift from mainly on-site to mainly off-site construction over the next 10 to 15 years. In countries with relatively demanding requirements on energy efficiency and air tightness, off-site construction has been dominating the market for more than 20 years. British Columbia adopted the BC Energy Step Code in 2017, a roadmap defining the energy efficiency of buildings over the coming years leading up to 2032, when all new construction will be required to be Net Zero ready. It is expected that the National Building Code of Canada will also encourage higher energy performance levels in the near future. Consequently, thermally better-performing envelopes will have to be produced and rigorous air tightness levels will have to be achieved for the sustainability goals given by the province. Envelope assemblies will get thicker, bulkier and heavier to meet these requirements. In this regard, a market shift to a greater amount of off-site construction is likely to be experienced to meet these targets in a controlled environment. This study is exploring the direct and indirect connections between sustainability and energy efficiency requirements given by codes to technical and cost-efficient solutions offered by industry.
\end{abstract}

\section{KEYWORDS}

2019 MOC Summit; Off-site construction; energy efficiency; building assemblies; BC Energy Step Code

\section{BACKGROUND}

The British Columbia Energy Step Code (herein referred to as the "Step Code") was introduced to the BC Building Code on December 15, 2017 and establishes energy performance targets for new Part 9 ( $\leq 3$ storeys, $\leq 600 \mathrm{~m}^{2}$ footprint) and Part 3 (>3 to 6 storeys, $>600 \mathrm{~m}^{2}$ footprint) residential buildings (Province of British Columbia, 2015). The Step Code provides the residential construction industry with discreet energy use, thermal energy demand and air tightness performance targets. Under the Step Code, five 'Steps' have been established for Part 9 residential buildings, and four for Part 3 residential buildings. The increasing performance targets begin with Step 1 (BC Building Code 2012 code minimum performance) and increase to 
Step 5 for Part 9 buildings and Step 4 for Part 3 buildings, with a final target of net-zero ready in 2032. In establishing the energy performance targets in this manner, designers and builders can utilize the building envelope and mechanical design of their choosing and are no longer restricted to prescriptive values as previously used under the provincial building code.

The BC Energy Step Code was created to provide consistent energy use, thermal energy demand and air tightness targets across all municipalities in the province of British Columbia. As of December $15^{\text {th }}, 2017$, all authorities having jurisdiction that operate under the BC Building Code can either opt to require or incentivize the performance targets presented in the Step Code and may no longer impose additional or alternative energy efficiency targets (Government of British Columbia, 2018). As per the provincial government's CleanBC announcement released on December $7^{\text {th }}, 2018$, the Step Code targets of Step 3 for Part 9, and Step 2 for Part 3 buildings will become the minimum performance targets for all municipalities across the province in 2022.

\section{BC Energy Step Code targets}

The energy efficiency targets established under the Step Code set upper limits on the energy use, thermal energy demand and air tightness performance results a new residential building may achieve. These targets are defined by air tightness, mechanical equipment and systems and building envelope construction and must be met independent of one another. The three performance requirements are described in further detail below. Note that for both the mechanical equipment and systems and building envelope targets which have been established, conditioned floor area is defined as that which falls inside of the thermal envelope, regardless of ceiling height, and includes interior partition walls (BC Building Code, 2012).

This paper will focus on and reference those sections of the BC Building Code which pertain to Part 9 buildings; however, it should be noted that the broader discussion regarding the implementation and intention of the Step Code pertains to all new residential construction. At the time writing, the Step Code applies to Part 3 multi-unit residential and large commercial buildings located in climate zone 4 only.

Air tightness. Specific targets have been set for Steps 2-5 for Part 9 buildings and are based on the results of on-site testing performed by a third-party consultant. Testing is performed using a blower door fan and associated manometer gauge to determine the rate at which air is able to pass through the air tight layer under an induced negative pressure. The results are presented in air changes per hour (ACH @ 50Pa.)

Mechanical equipment and systems. Targets for Part 9 buildings limit the total energy consumption of HVAC, domestic hot water, pumps and fans; they do not include baseloads such as plug load and lighting. The two compliance options are $\%<\mathrm{REF}$ (percent better than reference) or MEUI (mechanical use energy intensity). The MEUI target is measured on an energy consumption value given for the conditioned floor area of the home on an annual basis $\left(\mathrm{kWh} / \mathrm{m}^{2} * \mathrm{a}\right)$. The $\%<\mathrm{REF}$ target is measured using a compliant modeling software by a qualified third-party and compares the performance of the proposed house to the performance of an equivalent home built to code-minimum standards. The designer or builder has the option to use the performance data for either (not both) of these options when demonstrating compliance. 
Building Envelope. Targets established define the upper limits of annual heating demand a home may require. This metric emphasizes an enclosure-first approach and takes into consideration the energy gains and losses through the enclosure, internal heat gains and heat recovery efficiencies. The metric is labeled TEDI (thermal energy demand intensity) and is calculated as an annual energy demand value based on the conditioned floor area of the home $\left(\mathrm{kWh} / \mathrm{m}^{2} * \mathrm{a}\right)$.

The targets for the BC Energy Step Code have been established for each of the six climate zones located within the province. The climate zone map has been created by the National Research Council for use in the National Energy Code for Buildings (NECB) publication, and delineates its boundaries based on the annual number of heating degree days (C) a municipality experiences.

A full list of the required performance values can be found on the Step Code website at www.energystepcode.ca. The performance targets for municipalities found in climate zone 7A (5,000 to 5,999 HDD) have been included below (Table 1) for Step 4 and Step 5 for Part 9 buildings. Examples of municipalities located in climate zone 7A include Fort St John, Winnipeg, Quebec City and Banff (National Research Council of Canada, 2015).

Table 1. Step Code requirements for Part 9 buildings located in climate zone 7A (RDH Building Science Inc., 2018).

\begin{tabular}{|c|c|c|c|c|c|c|}
\hline \multicolumn{2}{|c|}{ Airtightness (ACH @ 50Pa) } & \multicolumn{2}{|c|}{$\%<\mathrm{REF}$ or MEUI } & \multicolumn{3}{|c|}{ TEDI $\left(\mathrm{kWh} / \mathrm{m}^{2 *} \mathrm{yr}\right)$} \\
\hline Step 4 & $\leq 1.5$ & \multicolumn{2}{|c|}{$40 \%$ or see below } & \multicolumn{3}{|c|}{55} \\
\hline Step 5 & $\leq 1.0$ & \multicolumn{2}{|c|}{ See below } & \multicolumn{3}{|c|}{35} \\
\hline \multicolumn{7}{|c|}{ MEUI Targets per Building Size, for Buildings with No Cooling System $\left(\mathrm{kWh} / \mathrm{m}^{2} * \mathrm{yr}\right)$} \\
\hline & $\leq 50 \mathrm{~m}^{2}\left(538 \mathrm{ft}^{2}\right)$ & $\begin{array}{l}\leq 75 \mathrm{~m}^{2} \\
\left(807 \mathrm{ft}^{2}\right)\end{array}$ & $\begin{array}{l}\leq 120 \mathrm{~m}^{2} \\
\left(1292 \mathrm{ft}^{2}\right)\end{array}$ & $\begin{array}{l}\leq 165 \mathrm{~m}^{2} \\
\left(1776 \mathrm{ft}^{2}\right)\end{array}$ & $\begin{array}{l}\leq 210 \mathrm{~m}^{2} \\
\left(2357 \mathrm{ft}^{2}\right)\end{array}$ & $\begin{array}{l}\leq 210 \mathrm{~m}^{2} \\
\left(2357 \mathrm{ft}^{2}\right)\end{array}$ \\
\hline Step 4 & 120 & 110 & 90 & 78 & 70 & 70 \\
\hline Step 5 & 95 & 85 & 70 & 60 & 55 & 55 \\
\hline
\end{tabular}

\section{DISCUSSION}

The 2018 Metrics Research Report by BC Housing presents energy conservation upgrade measures which may be used to achieve the required performance targets for six standard archetypes across all climate zones within the province (BC Housing, 2018). For the purpose of our study, we investigate the weight and volume of two above-grade exterior wall assemblies and one ceiling/roof assembly designed to meet the minimum performance targets for Step 4 and 5 for a medium single-family dwelling, $237 \mathrm{~m}^{2}\left(2551 \mathrm{ft}^{2}\right) 2$ storeys with basement, constructed in climate zone 7A. The values presented in the report have been calculated as lowest incrementalcost upgrade scenarios for the defined archetype but do not represent all possible combinations of upgrades which may be made to meet the minimum performance targets given in the Step Code. In investigating these three assemblies, we review the opportunities presented to the offsite construction industry in the construction of residential buildings designed to meet the targets of the BC Energy Step Code.

From the 2018 Metrics Report, we find the majority of the proposed energy conservation measures utilize an exterior wall assembly with an effective RSI of either 4.23 (R-24) or 7.04 (R- 
MOC SUMMIT / MAY 2019

40), while the proposed roof/ceiling assemblies range between an effective RSI of 10.57 (R-60) and $17.61(\mathrm{R}-100)$.

\section{Above-grade exterior wall assemblies}

The two proposed above-grade exterior wall assemblies constructed to meet the effective RSI values discussed in the 2018 Metrics Report include a split-insulation and deep-stud insulation assembly (Figure 2). The effective RSI values for two above-grade exterior wall assemblies have a lower range of RSI 3.87 (R-22) and can achieve in excess of RSI 10.57 (R-60), depending on the insulation types and depths used (RDH Building Science Inc., 2018).

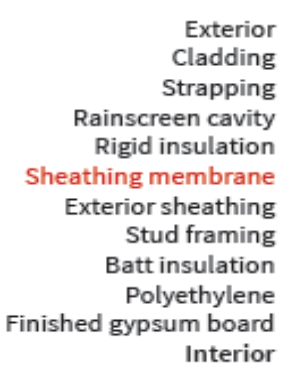

Interior

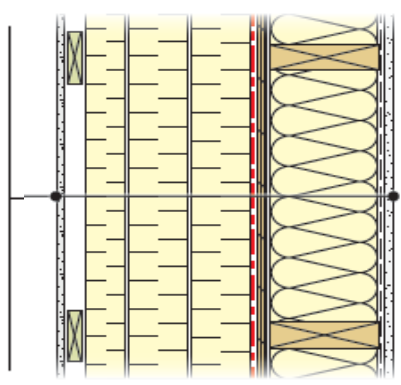

(a)

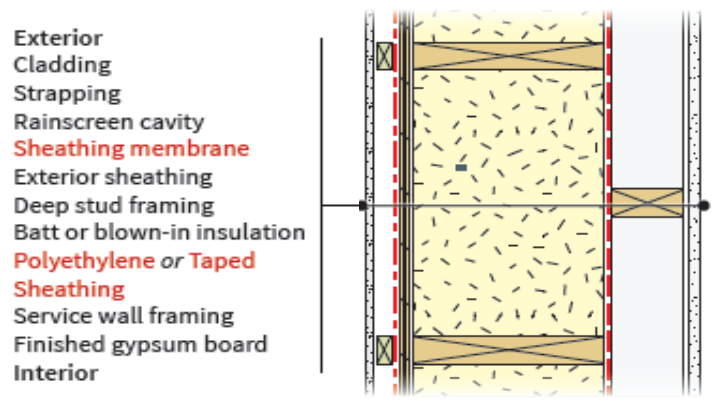

(b)

Figure 2. Above-grade exterior wall assembly systems that can be used to achieve high thermal performance targets, including (a) split insulation and (b) deep stud insulation

In consideration of the thermal and air tightness performance values given in the 2018 Metrics Research Report to meet the performance targets for Step 4 and Step 5 of the Step Code, we will investigate key design factors such as size, weight and detailing which must be taken into consideration for the construction of the assemblies shown in Figure 2.

\section{Split insulated wall with exterior insulation}

To achieve an effective RSI value of 4.23 (R-24) we propose an assembly system which utilizes a $38 \mathrm{~mm} \times 140 \mathrm{~mm}$ (2in x 6in) 406mm (16in) o.c framing cavity with a single bottom plate and double top plate insulated with mineral wool batt insulation (k-value $0.25 \mathrm{~W} / \mathrm{mK}$ (R-4/inch)) and a minimum of $50.8 \mathrm{~mm}$ (2.0in) of vapour-open semi-rigid exterior insulation (k-value 0.25 $\mathrm{W} / \mathrm{mK}(\mathrm{R}-4 / \mathrm{inch})$ ) installed on the exterior side of a single layer of $15.88 \mathrm{~mm}$ (5/8in) plywood sheathing. The installation of $19 \mathrm{~mm} \times 89 \mathrm{~mm}$ (1in $\times$ 4in) furring strips for a rain screen cavity will also be considered for total construction weight calculations. An effective RSI value of 4.26 (R-24.2) is achieved for this assembly (RDH Building Science Inc., 2018).

To achieve an effective RSI value of 7.04 (R-40) we propose a similar assembly, however a minimum exterior insulation depth of $152.4 \mathrm{~mm}$ (6.0in) must be used. An effective RSI value of 7.08 (R-40.2) is achieved for this assembly (RDH Building Science Inc., 2018).

Size. To simplify further calculations, we will consider an assembly panel measuring $1.2 \mathrm{~m} \mathrm{x}$ $2.4 \mathrm{~m}(4 \mathrm{ft} \times 8 \mathrm{ft})$. All framing members are calculated at $406 \mathrm{~mm}$ (16in) o.c. The total depth of 
the RSI 4.26 (R-24.2) and RSI 7.08 (R-40.2) split insulation walls described above is $225.7 \mathrm{~mm}$ (9in) and 327.23 (13in), respectively.

Weight. In calculating the weight of the proposed assemblies, we considered all assembly components excluding interior finishing (drywall), exterior cladding and membrane materials. The total weight of the proposed RSI 4.26 (R-24.2) wall assembly system is $86.14 \mathrm{~kg}(190.25 \mathrm{lbs})$ or $29.91 \mathrm{~kg} / \mathrm{m}^{2}\left(5.95 \mathrm{lbs} / \mathrm{ft}^{2}\right)$, while the weight of the proposed RSI 7.08 (R-40.2) wall assembly system is $107.43 \mathrm{~kg}(237.20 \mathrm{lbs})$ or $37.30 \mathrm{~kg} / \mathrm{m}^{2}\left(7.41 \mathrm{lbs} / \mathrm{ft}^{2}\right)$.

\section{Deep stud insulation wall}

To achieve an effective RSI-value of 4.23 (R-24) we propose an assembly system which utilizes a $38 \mathrm{~mm} \times 235 \mathrm{~mm}$ ( $2 \mathrm{in} \times 10 \mathrm{in}) 406 \mathrm{~mm}$ (16in) o.c. framing cavity with a single bottom plate and double top plate insulated with blown-in mineral fiber insulation (k-value $0.29 \mathrm{~W} / \mathrm{mK}(\mathrm{R}$ $3.4 /$ inch)) with an uninsulated $38 \mathrm{~mm} \times 89 \mathrm{~mm}$ (2in x 4in) interior service wall. A single layer of $15.88 \mathrm{~mm}(5 / 8 \mathrm{in})$ plywood sheathing is installed between the interior service wall and deep stud framing layer. The installation of $19 \mathrm{~mm} \times 89 \mathrm{~mm}$ (1in $\mathrm{x} 4 \mathrm{in}$ ) furring strips for a rain screen cavity will also be considered for total construction weight calculations. An effective RSI value of 4.63 (R-26.3) is achieved for this assembly (RDH Building Science Inc., 2018).

To achieve an effective RSI value of 7.04 (R-40) we propose a 302mm (11-7/8in) I-Joist (or equivalent) deep stud cavity wall utilizing blown-in mineral fiber insulation k-value $0.29 \mathrm{~W} / \mathrm{mK}$ (R-3.4/inch) and a $38 \mathrm{~mm} \times 89 \mathrm{~mm}$ (2in $\mathrm{x}$ 4in) structural service wall insulated with batt insulation (k-value $0.29 \mathrm{~W} / \mathrm{mK}$ (R-3.4/inch). A single layer of $15.88 \mathrm{~mm}$ (5/8in) plywood sheathing is installed between the interior service wall and deep stud framing layer. The installation of $19 \mathrm{~mm} \times 89 \mathrm{~mm}$ (1in x 4in) furring strips for a rain screen cavity will also be considered for total construction weight calculations. An effective RSI value of 7.08 (R-40.2) is achieved for this assembly (RDH Building Science Inc., 2018).

Size. To simplify further calculations, we will consider an assembly panel measuring $1.2 \mathrm{~m} \mathrm{x}$ $2.4 \mathrm{~m}(4 \mathrm{ft} \times 8 \mathrm{ft})$. All framing members are calculated at $406 \mathrm{~mm}$ (16in) o.c. The total depth of the RSI 4.63 (R-26.3) and RSI 7.08 (R-40.2) split insulation walls described above is $358.88 \mathrm{~mm}$ (14in) and $330.2(16.75 \mathrm{in})$, respectively.

Weight. In calculating the weight of the proposed assembly, we considered all components excluding interior finishing (drywall), exterior cladding, membrane materials and service cavity insulation, which is assumed to be installed on site. The total weight of the proposed RSI 4.63 (R-26.3) wall assembly system is $133.63 \mathrm{~kg}(294.591 \mathrm{bs})$ or $46.40 \mathrm{~kg} / \mathrm{m}^{2}\left(9.21 \mathrm{lbs} / \mathrm{ft}^{2}\right)$, while the weight of the proposed RSI 7.08 (R-40.2) wall assembly system is $132.35 \mathrm{~kg}$ (289.82lbs) or $45.95 \mathrm{~kg} / \mathrm{m}^{2}\left(9.06 \mathrm{lbs} / \mathrm{ft}^{2}\right)$.

\section{Code minimum comparison}

In consideration of the calculated weight of the proposed wall assemblies described above, we compare them to a standard construction assembly built to meet the minimum performance standards under the 2012 BC Building Code (assemblies in buildings with a heat recovery ventilator) for climate zone 7A. The proposed assembly is constructed using a $38 \mathrm{~mm} \times 140 \mathrm{~mm}$ (2in x 6in) $406 \mathrm{~mm}$ (16in) o.c framing cavity with a single bottom plate and double top plate 
insulated with mineral wool batt insulation (k-value $0.25 \mathrm{~W} / \mathrm{mK}$ (R-4/inch)), a single layer of $15.88 \mathrm{~mm}(5 / 8 \mathrm{in})$ plywood sheathing and $19 \mathrm{~mm} \times 89 \mathrm{~mm}$ (1in x 4in) furring strips for a rain screen cavity. An effective RSI value of 2.92 (R-16.6) is achieved for this assembly (FP Innovations, 2013). In calculating the weight of the assembly, we considered all components excluding interior finishing (drywall), exterior cladding and membrane materials. The total weight of the proposed code minimum wall assembly system is $75.5 \mathrm{~kg}$ (166.80lbs) or $26.22 \mathrm{~kg} / \mathrm{m}^{2}\left(5.21 \mathrm{lbs} / \mathrm{ft}^{2}\right)$.

\section{Roof assemblies}

The proposed ceiling/roof assembly constructed to meet the effective RSI value discussed in the 2018 Metrics Report is a split-insulation assembly (Figure 3). The effective RSI-value for the proposed assembly has a lower range of $8.01(\mathrm{R}-45.5)$ and can achieve in excess of 25.54 (R145), depending on the insulation types and depths used (RDH Building Science Inc., 2018).

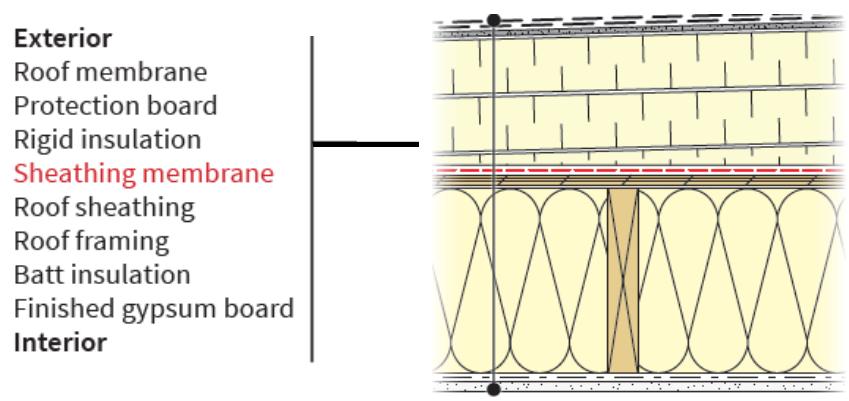

Figure 3. Roof/ceiling assembly that can be used to achieve high thermal performance targets.

In consideration of the thermal and air tightness performance values commonly cited in the 2018 Metrics Research Report, we will investigate key design factors such as size, weight and detailing which must be taken into consideration for the construction of the assembly shown in Figure 3.

\section{Split-insulated roof assembly}

To achieve an effective RSI value of 17.61 (R-100) we propose a 610mm (24in) roof truss at $406 \mathrm{~mm}$ (16in) o.c. framing insulated with blown-in insulation (k-value $0.29 \mathrm{~W} / \mathrm{mK}$ (R-3.4/inch)) and $191 \mathrm{~mm}$ (7.5in) of rigid mineral wool batt exterior insulation ((k-value $0.25 \mathrm{~W} / \mathrm{mK}(\mathrm{R}-$ 4/inch)). A single layer of $15.88 \mathrm{~mm}$ (5/8in) plywood sheathing is installed between the roof truss system and exterior insulation layer. An effective RSI value of 17.72 (R-100.6) is achieved for this assembly (RDH Building Science Inc., 2018).

Size. To simplify further calculations, we will consider an assembly panel measuring $1.2 \mathrm{~m} \mathrm{x}$ $2.4 \mathrm{~m}(4 \mathrm{ft} \times 8 \mathrm{ft})$. All framing members are calculated at $406 \mathrm{~mm}$ (16in) o.c. The total depth of the ceiling assembly described above is $816.90 \mathrm{~mm}$ (32in).

Weight. In calculating the weight of the proposed assembly we considered all components excluding interior finishing (drywall), exterior cladding, connections and membrane materials. 
The total weight of the proposed ceiling assembly is $271.83 \mathrm{~kg}(597.61 \mathrm{lbs})$ or $94.39 \mathrm{~kg} / \mathrm{m}^{2}$ $\left(18.681 \mathrm{bs} / \mathrm{ft}^{2}\right)$.

\section{Code minimum comparison}

In consideration of the calculated weight of the proposed roof/ceiling assembly described above, we compare it to a standard construction assembly built to meet the minimum thermal performance standards under the 2012 BC Building Code (assemblies in buildings with a heat recovery ventilator) for climate zone $7 \mathrm{~A}$. The proposed assembly is constructed using a $38 \mathrm{~mm} \mathrm{x}$ $235 \mathrm{~mm}$ (2in x 10in) $406 \mathrm{~mm}$ (16in) o.c flat roof assembly insulated with mineral wool batt insulation (k-value $0.25 \mathrm{~W} / \mathrm{mK}$ (R-4/inch)), a single layer of $15.88 \mathrm{~mm}$ (5/8in) plywood sheathing and $19 \mathrm{~mm} \times 89 \mathrm{~mm}$ (1in $\mathrm{x}$ 4in) furring strips for a ventilation cavity. An effective RSI value of 6.29 (R-35.7) is achieved for this assembly (FP Innovations, 2013). In calculating the weight of the assembly, we considered all components excluding interior finishing (drywall), exterior cladding and membrane materials. The total weight of the proposed code minimum ceiling assembly is $93.09 \mathrm{~kg}(205.291 \mathrm{bs})$ or $32.32 \mathrm{~kg} / \mathrm{m}^{2}\left(6.42 \mathrm{lbs} / \mathrm{ft}^{2}\right)$.

\section{Consideration of airtightness and vapour diffusion}

Air leakage through discontinuities in the primary air barrier can account for $30 \%$ or more of a home's heating and cooling costs and contribute to structural durability and indoor air quality problems (U.S. Department of Energy, 2019). Significant consideration will have to be given to the placement of the air barrier within the building envelope and the detailing work which will need to be done to achieve the airtightness targets in the Step Code. Additionally, vapour diffusion through exterior assemblies must be considered carefully to assure durability and occupant health. As the thickness of insulation in exterior assemblies increases, the temperatures in the outer layers of the envelope decrease. Over a depth of $12.5 \mathrm{~mm}(1 / 2 \mathrm{in})$, common sheathing materials, including plywood and oriented strand-board, are classified as a vapour barrier (National Research Council of Canada, 2010). As the depth of the thermal barrier increases in assemblies to meet higher performance targets, there is an increased risk for condensation on the interior surface of any material which is classified as a vapour barrier and is placed on the cold side of the dew point in the given assembly. As the thermal insulation layer is increased to meet the required performance targets of the Step Code, the importance of the use of materials with high vapour permeability on the cold side of the dew point increases significantly to ensure a high capacity for the assembly to dry out any moisture which has accumulated through the process of diffusion or air leakage across the assembly. Code compliant air tightness can be installed much easier, faster and more cost efficient in a controlled environment.

\section{Opportunities and considerations for modular and off-site construction}

The use of prefabricated (panel or modular) construction presents an opportunity to construct assemblies in a controlled environment and increase quality of airtight detailing to meet the required performance targets of the BC Energy Step Code. The recommended above-grade wall and ceiling/roof assemblies designed to meet Step 5 of the Step Code are 42 to $77 \%$ heavier and 87 to $100 \%$ thicker than the comparable assembly built to meet BC building code minimum today. Taking these factors into consideration, we can see considerable opportunity for the modular and off-site construction industry to meet the needs of the high-performance building industry in British Columbia as it moves towards a goal of net-zero ready construction in 2032. Besides the increase of quality control, this shift offers the potential of strongly increased 
productivity (World Economic Forum 2016) which can lead to a reduction of construction costs in the future.

\section{CONCLUSION}

The BC Energy Step Code demands higher thermal resistance which, when assuming the application of conventional insulation materials, triggers thicker envelope components. Compared to the current building code, the weight of above-grade wall and ceiling assemblies designed to meet Step 4 and Step 5 may increase by 42 to $77 \%$ while the volume may increase by 87 to $100 \%$, depending on the exact layout of the envelope components. The increase of volume, weight and airtight detailing can increase on-site construction time significantly; the adaptation of modern prefabrication can increase the productivity and offers better quality control to meet the requirements of the BC Energy Step Code.

\section{REFERENCES}

BC Building Code. (2012). British Columbia, Victoria: Queen's Printer of British Columbia.

BC Housing. (2018). Energy Step Code 2018 Metrics Research Full Report Update. Retrieved from Energy Step Code: http://energystepcode.ca/app/uploads/sites/257/2018/09/2018Metrics_Research_Report_Update_2018-09-18.pdf

FP Innovations. (2013). The Guide for Designing Energy-Efficient Building Enclosures for Wood-Frame Multi-Unit Residential Buildings in Marine to Cold Climate Zones in North America. Vancouver: FP Innovations.

Government of British Columbia. (2018, December 20). BC Energy Step Code. Retrieved from Government of British Columbia: https://www2.gov.bc.ca/gov/content/industry/construction-industry/building-codesstandards/energy-efficiency/energy-step-code

National Research Council of Canada. (2010). National Building Code of Canada. Ottawa: Government of Canada.

National Research Council of Canada. (2015). National Energy Code of Canada for Buildings. Ottawa, Ontario, Canada: First Printing.

Province of British Columbia. (2015). Understanding B.C.'s Building Regulatory System. Victoria: Office of Housing and Construction Standards.

RDH Building Science Inc. (2018). BC Energy Step Code Builder Guide. BC Housing.

U.S. Department of Energy. (2019). Air Sealing for New Home Construction. Retrieved from Energy.gov: https://www.energy.gov/energysaver/air-sealing-your-home/air-sealing-newhome-construction

World Economic Forum. (2016). Shaping the Future of Construction, A Breakthrough in Mindset and Technology 